\title{
Effects of La- and Pr-Substitution on the Structure and Superconductivity of $\mathrm{Ba}_{0.6} \mathrm{~K}_{0.4} \mathrm{BiO}_{3}$
}

\author{
Cui Yajing ${ }^{1}$, Chen Yongliang ${ }^{1}, \quad$ Cheng Cuihua ${ }^{2}, \quad$ Charles C. Sorrell ${ }^{2}$, Zhao Yong ${ }^{1,2}$ \\ ${ }^{1}$ Key Laboratory of Magnetic Levitation Technologies and Maglev Trains (Ministry of Education of China), Southwest Jiaotong University, \\ Chengdu 610031, China; ${ }^{2}$ University of New South Wales, Sydney 2052, Australia
}

\begin{abstract}
Two compositional series based on $\mathrm{Ba}_{0.6-y} \mathrm{La}_{y} \mathrm{~K}_{0.4} \mathrm{BiO}_{3}$ and $\mathrm{Ba}_{0.6-z} \mathrm{Pr}_{z} \mathrm{~K}_{0.4} \mathrm{BiO}_{3}$, with $y$ and $z$ being $0,0.025,0.05,0.1,0.2$, $0.3,0.4$, were synthesized using a molten salt method. X-ray powder diffraction data reveal that the initially undoped cubic crystal symmetry expands slightly to orthorhombic with Pr substitution but not with La substitution. A linearly reduction of the pseudo-lattice parameter following $a_{\mathrm{p}}=4.28257-0.02469 y(0.025 \leq y \leq 0.4)$ can be observed in $\mathrm{Ba}_{0.6-y} \mathrm{La}_{y} \mathrm{~K}_{0.4} \mathrm{BiO}_{3}$. A systematic decrease of the transition temperature, $T_{\mathrm{c}}$, is clarified by magnetic measurements and the superconductivity is finally vanished at $y, z$ $=0.2$ owing to the distortion of the crystal structure and the disproportionations of bismuth valence.
\end{abstract}

Key words: $\mathrm{Ba}_{0.6} \mathrm{~K}_{0.4} \mathrm{BiO}_{3}$; substitution; crystal structure; molten salt method

Since superconductivity near $30 \mathrm{~K}$ was discovered in a copper-free phase, $\mathrm{Ba}_{1-x} \mathrm{~K}_{x} \mathrm{BiO}_{3}(\mathrm{BKBO})^{[1,2]}$, this material has aroused considerable interest, although the mechanism of its superconductivity remains unclear. Further, it has been proved that it is difficult to prepare optimized superconducting BKBO owing to the volatility of the alkali, lack of reproducibility of composition and superconducting behavior, instability in air, and the variability in oxygen content ${ }^{[1,3]}$. BKBO has been reported to have a simple cubic perovskite structure ${ }^{[3]}$ that is free of the localized magnetic moments present in cuprate superconductors. It shares some of the characteristics of conventional superconductors, including the $s$-wave order parameter $^{[4]}$ and the superconducting gap $/ T_{\mathrm{c}}$ ratio of $2 \Delta / k_{\beta} T_{\mathrm{c}}=$ $3.5 \sim 4^{[5]}$, which is indicative of a moderately strong electron-phonon coupling limit. However, for $\mathrm{BKBO}$, the ratio between the superconducting carrier density and the effective mass ratio $\left(n_{\mathrm{s}} / \mathrm{m}^{*}\right)^{[6]}$ falls in the region characteristic of unconventional superconductors. Therefore, BKBO may provide the key to understanding the mechanism of unconventional superconductors.
Most previous work on $\mathrm{BaBiO}_{3}$ has concentrated on the introduction of superconductivity at low $T_{\mathrm{c}}$ by substitution on the Bi site using $\mathrm{Pb}^{[7]}$. Subsequently, superconductivity at high $T_{\mathrm{c}}$ was achieved by substitution on the Ba site using $\mathrm{K}^{[1,2,8]}$. Consequently, there is some uncertainty concerning the relative degrees of importance of the $\mathrm{Bi}$ and $\mathrm{Ba}$ sites to the introduction of charge carriers and consequent superconductivity in the parent electrically insulating compound $\mathrm{BaBiO}_{3}$. Since it is well known that doping of $\mathrm{YBa}_{2} \mathrm{Cu}_{3} \mathrm{O}_{7-x}$ with rare earths on the $\mathrm{Ba}$ site affects the superconducting properties ${ }^{[9]}$, this observation provides the driving force for the present work, which considers that the presumed substitution of the rare earths La and Pr for Ba may alter the structure and properties.

In the present work, $\mathrm{Ba}_{0.6-y} \mathrm{La}_{y} \mathrm{~K}_{0.4} \mathrm{BiO}_{3}$ and $\mathrm{Ba}_{0.6-z} \mathrm{Pr}_{z} \mathrm{~K}_{0.4} \mathrm{BiO}_{3}$ ( $y$ and $z=0,0.025,0.05,0.1,0.2,0.3,0.4$ ) samples were synthesized and characterized by X-ray diffraction and magnetization measurements. The effects of Pr and La doping on the crystal structure and superconductivity were assessed and compared to those of the undoped parent BKBO.

Foundation item: National Natural Science Foundation of China $(50872116,11004162,11104224)$; Research Fund for the Doctoral Program of Higher Education of China (20110184120029); Fundamental Research Funds for the Central Universities (SWJTU11BR063, 2682013CX004, 2682013ZT16, SWJTU11ZT31); National Magnetic Confinement Fusion Science Program (2011GB112001); Program of International S\&T Cooperation (2013DFA51050)

Corresponding author: Chen Yongliang, Ph. D., Associate Professor, Superconductivity and New Energy R\&D Center, Southwest Jiaotong University, Chengdu 610031, P. R. China, Tel: 0086-28-87601124, E-mail: 1lchen@swjtu.edu.cn 


\section{Experiment}

Powders of $\left(\mathrm{Ba}_{0.6-y} \mathrm{La}_{y}\right) \mathrm{K}_{0.4} \mathrm{BiO}_{3}$ and $\left(\mathrm{Ba}_{0.6-z} \mathrm{Pr}_{z}\right) \mathrm{K}_{0.4} \mathrm{BiO}_{3}(y$ and $z=0,0.025,0.05,0.1,0.2,0.3,0.4)$ were prepared via the molten salt method ${ }^{[10,11]}$ using $\mathrm{Ba}(\mathrm{OH})_{2} \cdot 8 \mathrm{H}_{2} \mathrm{O}, \mathrm{Bi}_{2} \mathrm{O}_{3}$, $\mathrm{NaBiO}_{3} \cdot 2 \mathrm{H}_{2} \mathrm{O}, \quad \mathrm{La}_{2} \mathrm{O}_{3}$, and $\operatorname{Pr}_{6} \mathrm{O}_{11}$ (suppliers). Previous work ${ }^{[10,11]}$ showed that an optimal $\mathrm{Bi}^{3+} / \mathrm{Bi}^{5+}$ ratio of $1 / 1.1966$ yielded the best homogeneity, so this ratio of 0.8357 was used. Consistent amounts of 0.06 moles (total) of mixed raw materials were dissolved in $20 \mathrm{~g}$ of liquid $\mathrm{KOH}$ in a Teflon crucible on a hot plate at $260{ }^{\circ} \mathrm{C}$ in air and maintained for $19 \mathrm{~h}$, with occasional stirring. The resultant slurry exhibited partial solubility, accompanied by a color change during heating. After decantation, the solid residue was washed sequentially with distilled water and then ethanol, followed by drying in air at $75^{\circ} \mathrm{C}$ for $24 \mathrm{~h}$. The crystallography was examined by X-ray diffraction (Philips X'Pert MRD diffractometer, $\mathrm{Cu} \mathrm{K \alpha}$ radiation) and the superconductivity was measured over the temperature range 5 50 K using a SQUID magnetometer (Quantum Design MPMS) in a magnetic field of $796 \mathrm{~A} / \mathrm{m}$.

\section{Results and Discussion}

Fig.1a shows the X-ray diffraction patterns of the series of $\mathrm{Ba}_{0.6-y} \mathrm{La}_{y} \mathrm{~K}_{0.4} \mathrm{BiO}_{3}$ samples. The slight peak splitting indicates that the structures are consistently quasi-cubic (tetragonal distortion). All diffraction peaks have been indexed although the assignment of the $\mathrm{BaCO}_{3}$ peak is, by necessity, open to question. It can be seen that a saturated solution is obtained at $y>0.3$. Although the exsolution of $\mathrm{Bi}$ as $\mathrm{Bi}_{2} \mathrm{O}_{3}$ at $y=0.4$ is clear, the relatively consistent height of the $\mathrm{BaCO}_{3}$ peak suggests that the solubility limit is not exceeded yet, and that this peak results from undissolved or recrystallized material. No exsolution of La-based compounds were observed.

Fig. 1b shows that the peak positions gradually shift to higher angles with increasing of dopant level at all levels, indicating that the lattice contracts (although no internal standard was used, the patterns were obtained in continuous runs). These peaks remain relatively consistent in width, indicating no essential change in either crystallinity or crystal structure.

On the basis of the experimental results for La-doping, the following comments are made: (1) $\mathrm{BaCO}_{3}$ and $\mathrm{Bi}_{2} \mathrm{O}_{3}$ are present as impurities in all compositions, without any trend in amounts, indicating that their presence is not associated with the doping. (2) La dissolves in the structure, as demonstrated by the alteration of the X-ray peak positions. (3) It is probable that the solid solution is substitutional since the lattice contracts. If the solid solution were interstitial, lattice expansion would be more likely. (4) Since $\mathrm{La}^{3+}$ is smaller than $\mathrm{Ba}^{2+}$ and $\mathrm{K}^{1+}$ but larger than $\mathrm{Bi}^{3+}$ and $\mathrm{Bi}^{5+}$, the lattice contraction is consistent with substitution on the $\mathrm{Ba}$ site. (5) It can be concluded that La substitutes on the $\mathrm{Ba}$ site from the beginning because the addition of $\mathrm{La}$ is compensated by the
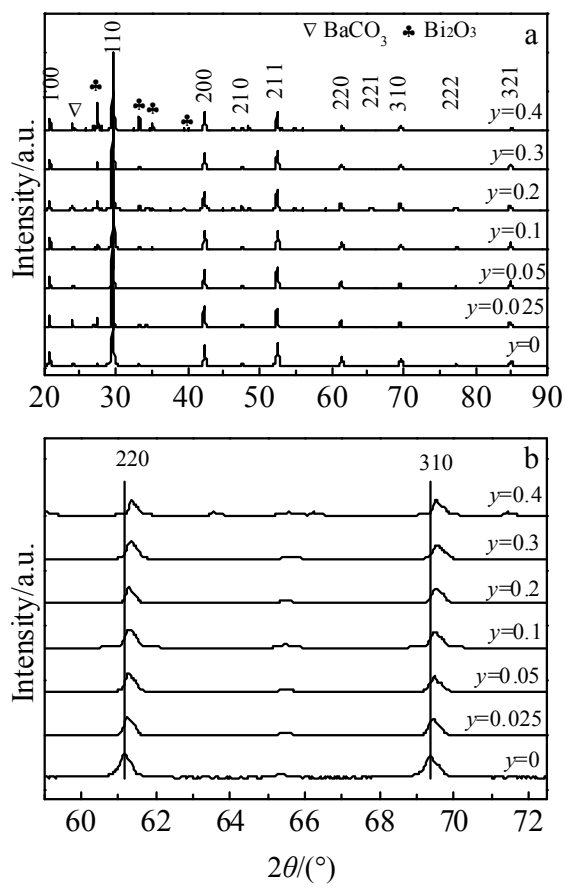

Fig.1 XRD patterns of the $\mathrm{Ba}_{0.6-y} \mathrm{La}_{y} \mathrm{~K}_{0.4} \mathrm{BiO}_{3}(y=0 \sim 0.4)$ samples (a); enlarged view of (220) and (310) peaks (b) (the line is just a guide to eyes)

reduction in the amount of $\mathrm{Ba}$ and no significant amounts of any compounds were exsolved at any compositions up to $y=0.3$.

In contrast, the $\mathrm{X}$-ray diffraction patterns of the series $\left(\mathrm{Ba}_{0.6-z} \mathrm{Pr}_{z}\right) \mathrm{K}_{0.4} \mathrm{BiO}_{3}$ samples shown in Fig.2a demonstrate that, in common with the La-doped materials, $\mathrm{BaCO}_{3}$ and $\mathrm{Bi}_{2} \mathrm{O}_{3}$ $\left(\mathrm{Bi}^{3+}\right)$ are present as impurities in all compositions, without any trend in amounts, indicating that their presence is associated with the raw materials and/or processing, not doping. However, the results of Pr doping are somewhat different from those of La doping in which they show the following: $\mathrm{Bi}^{4+}$ and $\mathrm{Pr}^{4+}$ are present in the form of $\mathrm{BiO}_{2}$ and $\mathrm{PrO}_{2}$, respectively, becoming detectable at $z=0.3 \sim 0.4$ and apparently increasing in proportion to dopant level, although the peaks are not sufficiently large to allow a definitive conclusion.

Fig. $2 \mathrm{~b}$ shows that the effects of Pr-doping on the crystal structure also are quite different from those of La-doping, as shown in Table 1. In this case, the structural effects are more significant as a function of increasing dopant level, with alteration of the quasi-cubic structure to a transient orthorhombic structure, followed by conversion to an expanded quasi-cubic structure that gradually contracts. In particular, the orthorhombic distortion is consistent with expansion in one direction (diffraction peak at lowest angle shifts significantly downwards) and contraction in the other two directions (diffraction peaks shift slightly upwards), probably resulting in a net unit cell expansion. Accordingly, it is concluded that 

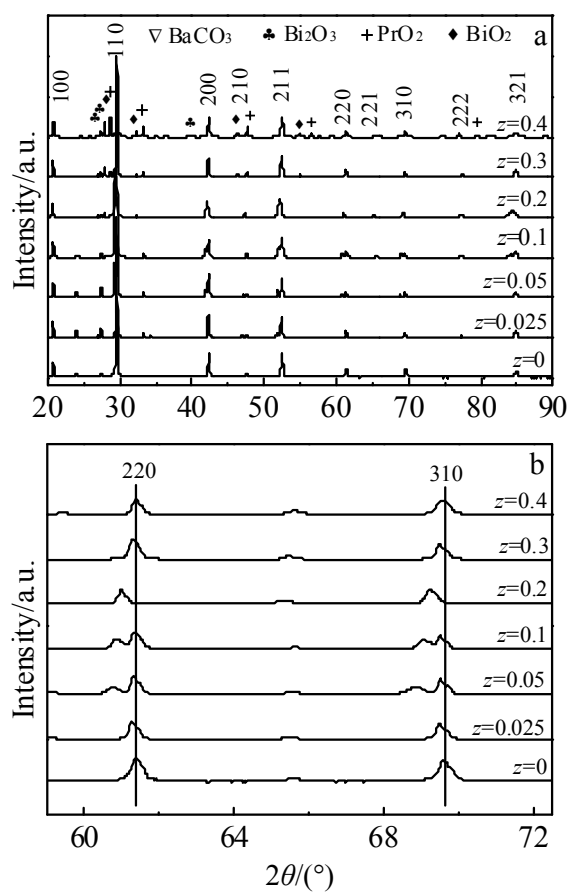

Fig.2 XRD patterns of the $\left(\mathrm{Ba}_{0.6-z} \mathrm{Pr}_{z}\right) \mathrm{K}_{0.4} \mathrm{BiO}_{3}(z=0 \sim 0.4)$ samples (a); enlarged view of (220) and (310) peaks (b) (the line is just a guide to eyes)

Table 1 Effect of Pr-doping on crystal structure in $\left(\mathrm{Ba}_{0.6-z} \mathrm{Pr}_{z}\right) \mathrm{K}_{0.4} \mathrm{BiO}_{3}$

\begin{tabular}{cc}
\hline Dopant level, $z$ & Structural distortion \\
\hline 0 & Parent quasi-cubic \\
$0.025,0.05,0.1$ & Orthorhombic distortion \\
$0.2,0.3,0.4$ & Expanded quasi-cubic with gradual lattice contraction \\
\hline
\end{tabular}

Pr dissolves in the structure and alters it, as demonstrated by the absence of reaction products or precipitates at the lowest levels of doping and the conversion from quasi-cubic to the orthorhombic distortion.

The structural distortion and the associated lattice expansion are consistent with one or both of the following solution mechanisms: substitution of the larger $\operatorname{Pr}^{3+}$ and/or $\mathrm{Pr}^{4+}$ ion on the smaller $\mathrm{Bi}^{5+}$ site (substitutional); solubility of the $\operatorname{Pr}^{3+}$ and/or $\operatorname{Pr}^{4+}$ ion in interstitial positions (Interstitial). Interstitial solid solubility is not likely owing to the relatively large sizes of $\mathrm{Pr}^{3+}$ and/or $\mathrm{Pr}^{4+}$. However, the X-ray data can be explained by substitutional solid solution formation according to the following considerations: $\mathrm{Pr}^{3+}$ and $\mathrm{Pr}^{4+}$ are sufficiently small to substitute for the larger $\mathrm{Ba}^{2+}$; this would cause a lattice contraction; substitution for the larger $\mathrm{Bi}^{3+}$ by the smaller $\operatorname{Pr}^{3+}$ and $\operatorname{Pr}^{4+}$ would result in lattice contraction; substitution for the smaller $\mathrm{Bi}^{5+}$ by the slightly larger $\operatorname{Pr}^{4+}$ (or larger $\operatorname{Pr}^{3+}$ ) would result in lattice expansion. Therefore, the anisotropic changes in axial dimensions and the consequent alteration of the quasi-cubic structure to the orthorhombic can be interpreted in terms of substitution for $\mathrm{Ba}$ and $\mathrm{Bi}$ by $\mathrm{Pr}$ occurring simultaneously.

Oxygen content is always a very important factor to determine the physical and chemical properties of oxide and oxygen vacancies which sometimes induce carriers in the system and sometimes disturb conduction. In the present work, we use the molten salt method to prepare all the samples where seldom oxygen vacancies were detected ${ }^{[10]}$. Therefore, it is concluded that our samples have no considerable oxygen deficiency and the contractions have been caused by the doping effect.

Fig.3 presents temperature dependence of the magnetic susceptibility. The transition temperature drops with the increase of the substitution level and vanishes when it reaches $y, z=0.2$ and the superconducting volume fraction both decreases with the increase of the substitution level, without consideration of a comparatively little signal of diamagnetic existing in the $y=0.2$ and $y=0.3$ samples for La substitution. Transition width becomes broader which suggests an in-homogeneity of the cations for La substitution. However, for Pr-substituted $\mathrm{Ba}_{0.6} \mathrm{~K}_{0.4} \mathrm{BiO}_{3}$, it shows better homogeneity than the La-substituted ones, presented in Fig.3b.

Fig.4 shows the change of the pseudo-lattice parameter with the substitution level. In general, perovskite compounds have various types of distortions such as tetragonal, orthorhombic, or monoclinic cells. Strictly speaking, we must take the lattice parameters for such distorted cells with real symmetries. Therefore, we use $a_{\mathrm{p}}$ (a lattice parameter assuming cubic
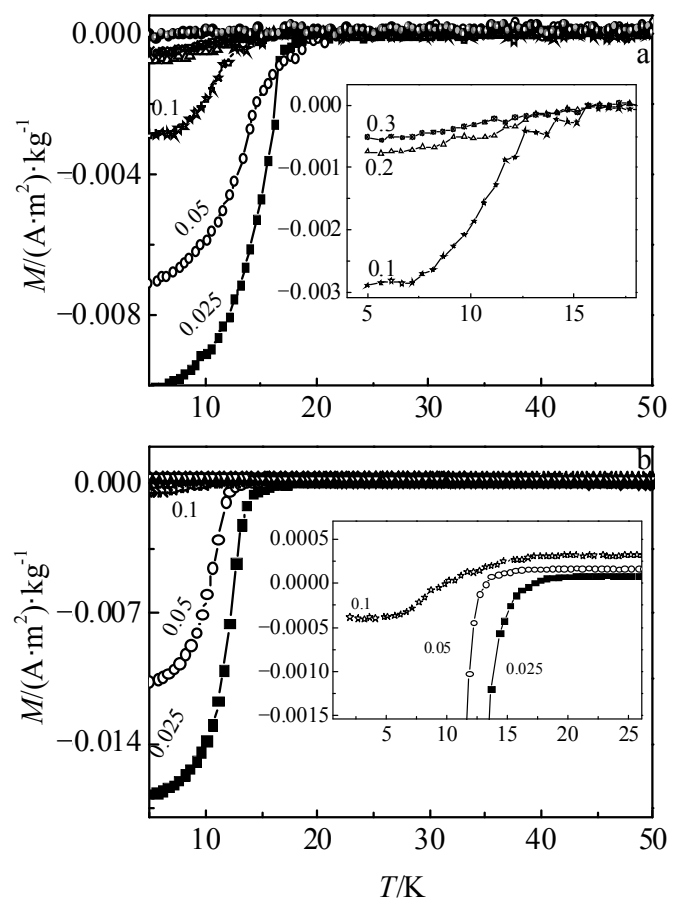

Fig.3 Temperature dependence of magnetic susceptibility for $\mathrm{Ba}_{0.6-y} \mathrm{La}_{y} \mathrm{~K}_{0.4} \mathrm{BiO}_{3}$ samples (a) and $\mathrm{Ba}_{0.6-\mathrm{z}} \mathrm{Pr}_{\mathrm{z}} \mathrm{K}_{0.4} \mathrm{BiO}_{3}$ samples (b) (Both are measured in an applied field of $796 \mathrm{~A} / \mathrm{m}$. Insets show enlarged view of the superconducting transition) 


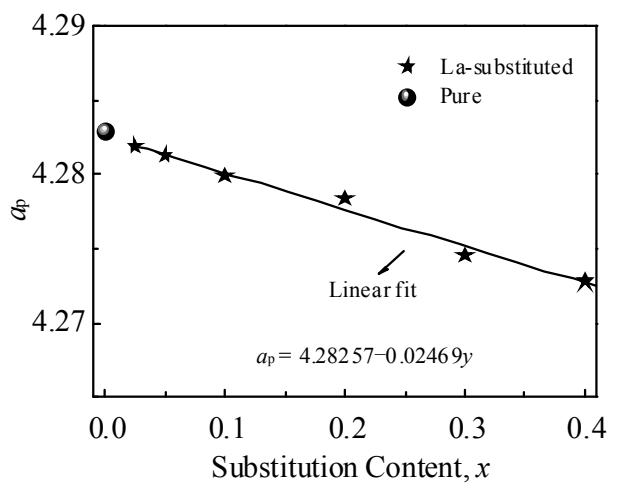

Fig.4 Pseudo-lattice parameter $a_{\mathrm{p}}$ dependence on substitution level of $\mathrm{La}$

perovskite) as an indicator of the cell size in the present work. With the increase of La substitution, lattice parameters are reduced probably due to a decrease in the averaged ionic radius of A-site element in the perovskite-type compounds. We have fitted the drop with linear, and it is not as sharp as the doping with $\mathrm{K}$ content in $\mathrm{Ba}_{1-x} \mathrm{~K}_{x} \mathrm{BiO}_{3}$. It has been reported that the drop of $a_{\mathrm{p}}$ with $\mathrm{K}$ content is coincident with $a_{\mathrm{p}}=4.3548-0.1743 x \quad(0.3 \leq x \leq 0.6)^{[3]}$, but La-substituted $\mathrm{Ba}_{1-y} \mathrm{La}_{y} \mathrm{~K}_{0.4} \mathrm{BiO}_{3}$ just follows the equation of $a_{\mathrm{p}}=4.28257-$ $0.02469 y \quad(0.025 \leq y \leq 0.4)$. Obviously, the effect of $\mathrm{La}$ substitution is not as sensitive as $\mathrm{K}$ doping.

It has been concluded in our previous work that the deficiency of $\mathrm{Ba}(\mathrm{OH})_{2} \cdot 8 \mathrm{H}_{2} \mathrm{O}$ in the starting materials may influence superconductivity of BKBO ${ }^{[10]}$. Fig.5 displays the reduction of $T_{\mathrm{c}}$ with increasing mass ratio of $\mathrm{Ba}(\mathrm{OH})_{2} \cdot 8 \mathrm{H}_{2} \mathrm{O} / \mathrm{KOH}\left(\gamma_{\mathrm{w}}\right)$ in the present work. The $T_{\mathrm{c}}$ of $\mathrm{Ba}_{0.6} \mathrm{~K}_{0.4} \mathrm{BiO}_{3}$ (30.6 K, see Fig.5 inset) and $\mathrm{Ba}_{0.4} \mathrm{~K}_{0.6} \mathrm{BiO}_{3}(7.2$ $\mathrm{K})$ in our preliminary study of $\mathrm{Ba}_{1-x} \mathrm{~K}_{x} \mathrm{BiO}_{3}$ are also presented ${ }^{[10]}$, showing comparing data with the $\mathrm{La}$ and $\mathrm{Pr}$ substitution samples. They show totally different behaviors. According to this, we can conclude that the substitution in our present work has a real effect on the transition temperature, not for the deficiency of $\mathrm{Ba}(\mathrm{OH})_{2} \cdot 8 \mathrm{H}_{2} \mathrm{O}$ in the starting materials.

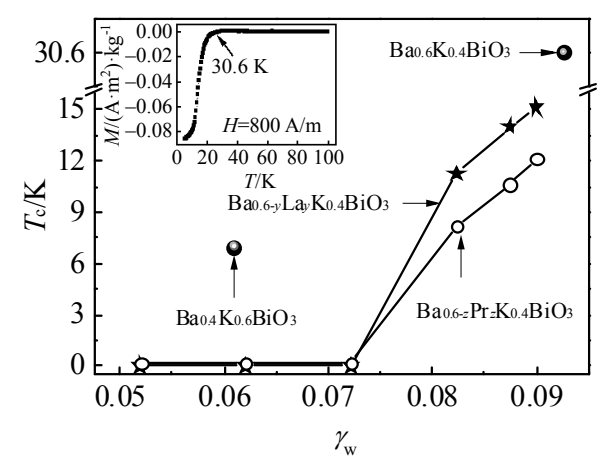

Fig.5 Reduction of transition temperature $T_{\mathrm{c}}$ with decreasing mass ratio of $\mathrm{Ba}(\mathrm{OH})_{2} \cdot 8 \mathrm{H}_{2} \mathrm{O} / \mathrm{KOH}\left(\gamma_{\mathrm{w}}\right.$ ) (the $T_{\mathrm{c}}$ of $\mathrm{Ba}_{0.6} \mathrm{~K}_{0.4} \mathrm{BiO}_{3}$ and $\mathrm{Ba}_{0.4} \mathrm{~K}_{0.6} \mathrm{BiO}_{3}$ were also presented to show comparison)
In the present two systems, the carrier concentration changes with the substitution at Ba-site. The replacing of every two $\mathrm{Ba}^{2+}$ ions by $\mathrm{La}^{3+}$ or $\mathrm{Pr}^{3+}$ ones produces two electrons, suggesting a break of hole pair in oxygen environment of bismuth. In that case, the hole-carrier density decreases and induces a suppression of $T_{\mathrm{c}}$. Partial substitution of $\mathrm{La}$ and $\mathrm{Pr}$ for $\mathrm{Ba}$ or $\mathrm{Bi}$ induces not only a decrease of hole-carrier concentration but also a structural distortion. There have been reports on $\mathrm{BaBiO}_{3}$ that $\mathrm{Bi}$ occupies two distinctive sites with different bond lengths and suggested the $\mathrm{Bi}$ valence disproportionation $\mathrm{Ba}_{2}\left(\mathrm{Bi}^{3+} \mathrm{Bi}^{5+}\right) \mathrm{O}_{6}$ using neutron diffraction ${ }^{[12]}$. The performed X-ray absorption spectroscopy (XAS) measurements ${ }^{[13-15]}$ proposed a charge disproportionation model in the form: $2 \mathrm{Bi}^{4+} \rightarrow \mathrm{Bi}^{3+}+\mathrm{Bi}^{3+} \mathrm{L}^{2}$, where $\mathrm{L}^{2}$ denotes the pair of holes in oxygen octahedral environment. These two different surroundings of the $\mathrm{Bi}$ ion produce two different $\mathrm{Bi}$ octahedrons, a stiff small octahedron and a soft large one. For $\mathrm{Ba}_{0.6} \mathrm{~K}_{0.4} \mathrm{BiO}_{3}$, the addition of $\mathrm{Bi}^{3+} \mathrm{L}^{2}$ increases the input of the stiff small octahedron and has no tilting distortion. On the contrary, La- and Pr-substituted $\mathrm{Ba}_{0.6} \mathrm{~K}_{0.4} \mathrm{BiO}_{3}$ on the $\mathrm{Ba}$ site as well as $\mathrm{Pr}^{4+}$ substitution on the $\mathrm{Bi}^{5+}$ site produce a decrease of the stiff small octahedron and enhance the tilting distortion.

Furthermore, the distortion is not only related to the valence of the substitution but also to the radius of the substituted element. Antipov and Kazakov ${ }^{[16,17]}$ reported the superconductivity of $\mathrm{Sr}_{1-x} \mathrm{~K}_{x} \mathrm{BiO}_{3}$ and $\mathrm{Sr}_{1-x} \mathrm{Rb}_{x} \mathrm{BiO}_{3}$ which show that the octahedral tilt scheme influenced by the size of the A cation is also an important aspect. In our present work, the radius of $\mathrm{La}$ and Pr cations are all smaller than the Ba ones and enhance the octahedral distortion leading to charge disproportionation and suppression of superconductivity. Compared with Lasubstituted BKBO system, the simultaneous influence of $\mathrm{Pr}^{4+}$ substitution at the $\mathrm{Bi}^{5+}$ site has significantly enhanced the distortion of crystal structure and the charge disproportionation in Pr-substituted $\mathrm{Ba}_{0.6} \mathrm{~K}_{0.4} \mathrm{BiO}_{3}$ system. Consequently, $\mathrm{Pr}$ substitution has induced a larger suppression of $T_{\mathrm{c}}$ in $\mathrm{BKBO}$.

\section{Conclusions}

1) A series of $\mathrm{Ba}_{0.6-y} \mathrm{La}_{y} \mathrm{~K}_{0.4} \mathrm{BiO}_{3}$ and $\mathrm{Ba}_{0.6-z} \mathrm{Pr}_{z} \mathrm{~K}_{0.4} \mathrm{BiO}_{3}$ with $y, z=0,0.025,0.05,0.1,0.2,0.3,0.4$ can be prepared by a molten salt method.

2) With La substitution, lattice parameters are linearly reduced for all the La contents. However, the alternation of crystal structure from quasi-cubic to orthorhombic structure can be observed in the Pr-substituted BKBO.

3) $T_{\mathrm{c}}$ is found to be suppressed at a relatively low substitution level $y, z \leq 0.1$ and vanished when $0.2 \leq y$ or $z \leq$ 0.4 . The distortion of the crystal structure owing to the valence of the substitution and the radius of the substituted element is recognized as the reason of the $T_{\mathrm{c}}$ suppression.

\section{References}

1 Cava R J, Batlogg B, Krajewski J J et al. Nature[J], 2008, 332: 
814

2 Mattheiss L F, Gyorgy E M, Johnson D W. Phy Rev B[J], 1988, 37: 3745

3 Pei S Y, Jorgensen J D, Dabrowski B et al. Phys Rev B[J], 1990, 41: 4126

4 Bravner D A, Manser C, Ott H R. Phys Rev B[J], 1997, 55: 2788

5 Martin S, Hellman E S, Kussmaul E H et al. Phys Rev B[J], 1993 , 47: 14510

6 Uemura Y J, Le L P, Luke G M et al. Phys Rev Lett[J], 1991, 66: 2665

7 Sleight A W, Gillson J L, Bierstedt P E. Solid State Commun[J], 1975, 17: 27

8 Prijamboedi B, Hiromoto Uwe. Physica C[J], 2001, 357-360: 252

9 Sun X F, Rui X F, Wang F et al. Journal of Physics: Condensed
Matter[J], 2004, 16: 2065

10 Chen Y L, Cui Y J, Wang F S et al. Physica C[J], 2011, 471: 704

11 Cui Y J, Chen Y L, Wang F S et al. Rare Metal Materials and Engneering[J], 2009, 38(4): 583 (in Chinese)

12 Cox D E, Sleight A W. Solid State Commun[J], 1976, 19: 969

13 Menushenkov A P, Ignatov A Y, Klementev K V et al. Physica $B[\mathrm{~J}], 1995,208: 295$

14 Menushenkov A P. Nucl Instr Meth Phys Res A[J], 1998, 405: 365

15 Menushenkov A P, Klementev K V, Konarev P V et al. Nucl Instr Meth Phys Res $A[\mathrm{~J}], 2000,448: 340$

16 Antipov E V, Khasanova N R, Pshirkov J S et al. Current Applied Physics[J], 2002(2): 425

17 Kazakov S M, Chaillout C, Bordet P et al. Nature[J], 1997, 390: 148

\title{
$\mathrm{La}$ 和 $\mathrm{Pr}$ 掺杂对 $\mathrm{Ba}_{0.6} \mathrm{~K}_{0.4} \mathrm{BiO}_{3}$ 结构及超导电性的影响
}

\author{
崔雅静 ${ }^{1}$, 陈永亮 ${ }^{1}$, 程翠华 ${ }^{2}$, Charles C. Sorrell ${ }^{2}$, 赵 勇 ${ }^{1,2}$ \\ (1. 西南交通大学 磁浮技术与磁浮列车教育部重点实验室, 四川 成都 610031)
}

(2. 新南威尔士大学, 澳大利亚 悉尼 2052)

\begin{abstract}
摘 要: 利用熔盐法制备了 $\mathrm{Ba}_{0.6-y} \mathrm{La}_{y} \mathrm{~K}_{0.4} \mathrm{BiO}_{3}$ 和 $\mathrm{Ba}_{0.6-z} \mathrm{Pr}_{z} \mathrm{~K}_{0.4} \mathrm{BiO}_{3} 2$ 个系列的样品, 其中 $\mathrm{La}$ 和 $\mathrm{Pr}$ 的掺杂量 $y$ 和 $z$ 分别为 $0,0.025,0.05,0.1$, $0.2,0.3,0.4$ 。X 射线粉末衍射结果显示, Pr 掺杂使得 $\mathrm{BKBO}$ 晶体结构由最初的立方晶系转变成为正交晶系, 但是 $\mathrm{La}$ 掺杂样品却没有发 生此种晶体结构的变化。 $\mathrm{La}$ 掺杂样品 $\mathrm{Ba}_{0.6-\mathrm{y}} \mathrm{La}_{y} \mathrm{~K}_{0.4} \mathrm{BiO}_{3}$ 的准晶格参数 $a_{\mathrm{p}}$ 随掺杂量的增大而线性减小, 其变化遵循 $a_{\mathrm{p}}=4.28257-0.02469 y$ $(0.025 \leq y \leq 0.4)$ 的规律。样品磁性测量结果表明, 掺杂样品的超导转变温度 $T_{\mathrm{c}}$ 均随着掺杂量的增大而系统性地减小, 并且当掺杂量达到 0.2 时, 2 个系统中的超导转变均消失。认为掺杂引起的晶体结构扭曲及铋化合价的不均衡导致了 BKBO 掺杂系统超导电性的变化。 关键词: $\mathrm{Ba}_{0.6} \mathrm{~K}_{0.4} \mathrm{BiO}_{3}$; 掺杂; 晶体结构; 熔盐法
\end{abstract}

作者简介: 崔雅静, 女, 1982 年生, 博士, 副研究员, 西南交通大学超导与新能源研究开发中心, 四川 成都 610031, 电话: 028-87601124, E-mail: cyjing@home.swjtu.edu.cn 